\title{
Charity calls for funding boost to dentistry as it tops list of most delayed health services
}

$\mathrm{N}$ ew research collected by the Ora Health Foundation has found further evidence of an NHS dental service in crisis. ${ }^{1}$ The oral health charity is now calling on ministers to promptly address the issue of backed up dental appointments and provide the support NHS dentistry needs to get back on track.

A survey of over 2,000 British adults has found that almost half (45\%) reported delays to their dental appointments or treatments in the last 12 months. This is more than any other health service including GP surgeries $(30 \%)$, hospital services (16\%) and mental health support (11\%).

Latest figures suggest that as many as 20 million dental appointments have been delayed or cancelled since March 2020.

Dr Nigel Carter OBE, Chief Executive of the Oral Health Foundation, believes that vital funding and support is needed for NHS dentistry to avoid the nation sleepwalking into an oral health crisis.

Dr Carter said: 'Dentistry has been severely underfunded for many years and services have suffered greatly during the pandemic. To address the backlog caused by COVID-19-19 restrictions, and to ensure dentistry does not fall behind other crucial health services, now is the time for government to provide more funding and invest in the nation's oral health.

'Regular dental visits are key for maintaining good oral health. Dentists can spot oral health problems in the early stages and provide patients with advice and care that can save them from both invasive and expensive treatments later down the line.

'Dentists also conduct potentially lifesaving mouth cancer checks as part of every routine appointment. Many people are unaware when it comes to mouth cancer symptoms and how to look for it and therefore the only mouth cancer check they'd get is when they have their regular appointment.'

As a result of delays to dentistry over the last year, one-in-ten (12\%) people have accessed remote dentistry services in the last 12 months. This includes telephone advice, video calls and emails with their dental team.

Despite the ease of remote advice services, three-in-four (74\%) say they prefer physical appointments with their dental team. This was much higher than for general health, where just over half (59\%) said that they would prefer physical appointments.

Despite a reduction in services over the last year, the charity is keen to get more Brits back into the dental chair.

Dr Carter added: 'Dental professionals have done an excellent job adapting during the pandemic in spite of very difficult challenges. The good news is that many dentists, dental hygienists and therapists, are now able to see fare more patients than they were last summer, and the range of treatments available should be back to normal.'

\section{Reference}

1. Oral Health Foundation, 'National Smile Month Survey 2021', UK, Broadcast Revolution, April 2021, Sample 2,009.

\section{Dentists greet 'no brainer' investment to boost access and future proof services}

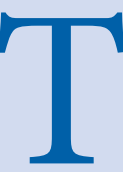
he British Dental Association Scotland has welcomed confirmation the Scottish Government will allocate $£ 5$ million to help practices invest in ventilation equipment to increase patient volumes while meeting COVID-19 restrictions.

The BDA first made the bid for financial support to improve ventilation to the Scottish Government in November. England is now the only UK nation not to have committed any capital funding for ventilation to help restore services.

Chief Dental Officer Tom Ferris has confirmed funds can be used to purchase, renew or upgrade ventilation systems, and practices can claim retrospectively for the period 1 April 2020 - 31 March 2022. The BDA is awaiting details of the conditions applied to the scheme but has expressed concern that it may not cover those practices who have already installed portable units or air cleaners when they were unable to improve ventilation by other means in the short term, following guidance from the Scottish Dental Clinical Effectiveness Programme (SDCEP).

Many in this position are based in sites unsuitable for major works, such as premises owned by health boards, in densely packed city centres with adjoining residential and commercial units, or in listed properties.

To meet strict guidelines on COVID-19 transmission, dentists have had to leave surgeries fallow between most common procedures. Investment in ventilation ensures practices can reduce these gaps and increase patient throughput.

Restrictions have left practices operating at a fraction of their former capacity. Data from Public Health Scotland have shown a dramatic reduction in NHS dentistry delivered, which has hit those in most deprived communities the hardest. Between April and November 2020, the number of courses of treatment delivered was $83 \%$ lower than during the same period in 2019.

Scotland's CDO joined colleagues from the other three UK nations to commit to reviewing current restrictions. While the review may reduce the need for a fallow time longer-term, the BDA has stressed this investment is required to 'future proof' services in the advent of any future pandemic, to secure an immediate boost in access, and will prove cost-neutral through increased patient charge revenues.

David McColl, chair of the British Dental Association's Scottish Dental Practice Committee said: 'This is a no-brainer from the Scottish Government. Investment in ventilation can future proof Scotland's dental services, boost patient numbers, and pay for itself.

'We must avoid half measures. Many dentists have had no option but to buy portable systems to get patients back through their doors. Ministers must ensure they do not lose out.

'For our patients' sake, this needs to mark a turning point when it comes to providing ongoing support to practices. A signature policy on free dentistry for all will be a promise that can't be kept unless we see real commitment from ministers. 